\title{
How clayey fines in aggregates influence the properties of lime mortars
}

\author{
Frank Winnefeld · Karl Georg Böttger
}

Received: 1 September 2004 / Accepted: 16 February 2005

(C) RILEM 2006

\begin{abstract}
Despite the fact that the maximum content of fines in aggregates is restricted in national and international standards, the use of unwashed sands in restoration mortars is often demanded by restorers due to their colouring properties. The colour of these aggregates may be caused by clay minerals in the fine fraction below $63 \mu \mathrm{m}$. Hence, this study aims to determine the influence of loam and clay contents in a quartz aggregate on the properties of fresh and hardened limeand lime-cement-mortars. The experimental results revealed that the main effect of clay fines in aggregates is an increase of the water demand for a constant mortar consistency. As a consequence, the higher water/binder ratio causes a strong decrease of the mortar quality with respect to mechanical, hygral and durability properties.
\end{abstract}

Résumé Bien que la teneur maximale en fines des granulats soit limitée par des normes nationales et internationales, l' utilisation de sables non lavés dans les mortiers de restauration est souvent demandée par les restaurateurs du fait de leur effet colorant. La couleur de ces sables est toutefois souvent due à leur teneur en minéraux argileux dans leur fraction fine $<63 \mu \mathrm{m}$. La

Frank Winnefeld

Empa, Swiss Federal Laboratories for Materials Testing and Research, Switzerland

Karl Georg Böttger

University of Siegen, Germany présente étude avait pour but de déterminer l'influence de la teneur en argile de granulats de quartz sur les caractéristiques du mortier frais et du mortier durci de mortiers de chaux et de mortiers bâtards. Cette étude a permis de mettre en évidence que l' effet principal des fines argileuses des granulats est d'augmenter la teneur en eau nécessaire pour obtenir une consistance égale du mortier. Cette augmentation de la teneur en eau provoque une nette diminution de la qualité du mortier pour ce qui est de ses caractéristiques de résistance mécanique, de résistance à l' humidité et de durabilité.

\section{Introduction}

When using restoration mortars for historical buildings, often a colour adaptation of the new mortars to the old material is required. This can be done - besides the use of pigments - especially by the application of coloured sands. However, the colour of these aggregates is often caused by clay minerals in the fine fraction below $63 \mu \mathrm{m}$. Furthermore, the analysis of historical mortars reveals high contents of a clay fine fraction in the aggregates in some cases, leading to the conclusion that unwashed pit sands were used [1]. On the basis of this data unwashed sands are used in some laboratory studies on the development of restoration mortars [2] and even lead to the recommendation to use such aggregates in the field [3]. 
Other authors mention, that unwashed sands usually improve the mortar workability due to their clay content, but do not recommend their use in the field, as they reduce mortar durability [4, 5]. Clay fines or clay lumps are regarded as undesirable harmful aggregate constituents. They cause a high water demand of the mortar leading to a reduction in strength and durability [6, 7]. They show a strong adhesion to the coarse aggregate grains and thus decrease the bonding between the hydrated binder matrix and aggregate.

Although calcined clays are much more reactive to alkaline solutions, uncalcined clays release $\mathrm{Al}$ and $\mathrm{Si}$ ions into the solution [8]. In the presence of calcium hydroxide, calcium silicate hydrates and/or calcium aluminate hydrates are formed [9]. Due to this reactivity, the sulphate resistance of the mortar may be influenced negatively.

Concerning restoration mortars this is a very important point as historical buildings are often highly contaminated with soluble sulphates. Some historical buildings e.g., in northern Germany had even been constructed using gypsum or gypsum lime mortars. Restoration mortars with a low sulphate resistance are not suitable in these cases. Laboratory studies revealed that clay minerals are able to act as aluminium source for the formation of the expansive phase ettringite [10]. A damage case caused by ettringite formation from clay agglomerates in a gypsumlime mortar shows this potential very clearly [11]. Other authors found an ettringite formation caused by clay agglomerates in a failed cement-treated base pavement [12]. Hence, the use of unwashed sands may decrease the sulphate resistance of a restoration mortar.

European standard EN 13139 on mortar aggregates assesses the fines in appendix A. Fines can be considered non-harmful when the total fines content in the fine aggregate (sand) is below 3\% (or other value according to the provisions valid in the place of use of the aggregate), or the sand equivalent value or the methylene blue test do not exceed certain limits.

To study the effect of clay fines in aggregates, the influence of loam and clay contents of grain size below $63 \mu \mathrm{m}$ on the properties of fresh and hardened lime based mortars was investigated. The experiments were carried out on mortars with a constant consistency, representing the field conditions in restoration practice.

\section{Materials and methods}

\subsection{Materials}

To cover the whole range of binders used for the restoration of historical masonry, three hydrated limes (one white lime and two natural hydraulic limes) and two lime-cement mixtures were studied:

-hydrated white lime CL 90 according to European standard EN 459-1, specific surface $18700 \mathrm{~cm}^{2} / \mathrm{g}$ according to EN 196-6 (Blaine method)

-hydrated natural hydraulic lime NHL 2, specific surface $10600 \mathrm{~cm}^{2} / \mathrm{g}$

-hydrated natural hydraulic lime NHL 5, specific surface $12600 \mathrm{~cm}^{2} / \mathrm{g}$

-mixture of white lime CL 90 with high sulphate resistant Portland cement CEM I 42.5 N - HS according to EN 197-1 (specific surface of the cement: 4100 $\mathrm{cm}^{2} / \mathrm{g}$ ), proportions $75 / 25$ by weight $=$ binder LPC

-mixture of white lime CL 90 with high sulphate resistant Portland blastfurnace slag cement CEM III/B $32.5 \mathrm{~N}-\mathrm{NW} / \mathrm{HS}$ according to EN 197-1 (specific surface of the cement: $3800 \mathrm{~cm}^{2} / \mathrm{g}$ ), proportions $75 / 25$ by weight $=$ binder LSC

The following aggregates were used:

-standard quartz sand 0-2 mm according to EN 196-1 -standard sand with addition of 4 and 8 mass- $\%$ loam -standard sand with addition of 2, 4, 6 and 8 mass- $\%$ kaolin

The phase compositions of loam and kaolin were determined by X-ray diffraction analysis (Table 1). The specific surfaces were measured using the Blaine method.

The binder/aggregate ratio was $1: 5$ by weight. Table 2 gives the compositions of the mortar mixes examined in this study.

Table 1 Phase composition and fineness of loam and kaolin

\begin{tabular}{lll}
\hline mineral phase $/$ mass-\% & loam & kaolin \\
\hline illite + muskovite & 12 & 0 \\
kaolinite + clinochlore & 18 & 96 \\
quartz & 70 & 1 \\
orthoclase & 0 & 3 \\
specific surface $/ \mathrm{cm}^{2} / \mathrm{g}$ & 7000 & 12600 \\
\hline
\end{tabular}


Table 2 Mix proportions, fresh mortar properties, strength and length change of hardened mortar

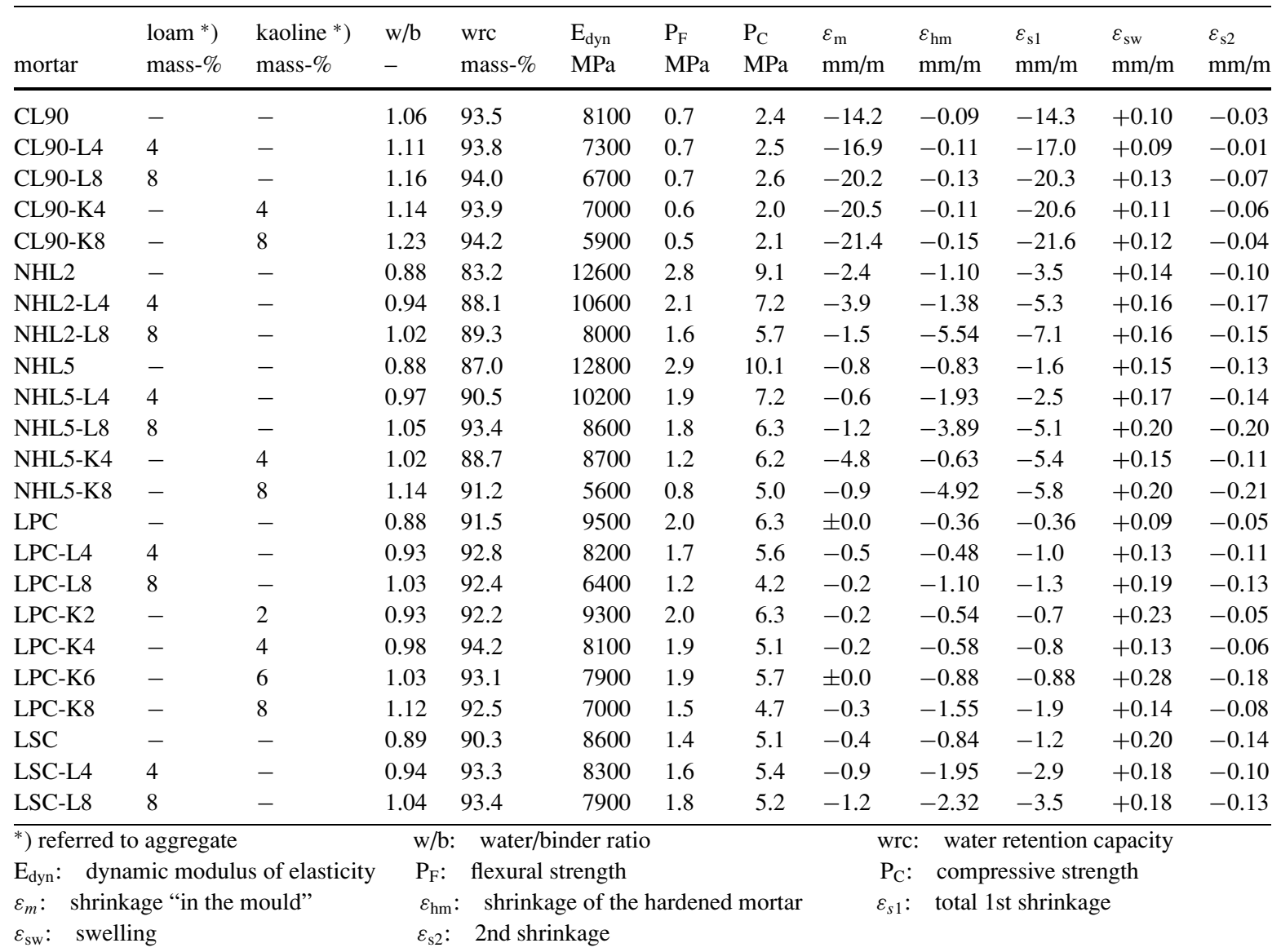

\subsection{Mortar mixing and curing}

The mortars were mixed according to EN 196-1. Their water/binder ratios were adjusted to a flow of $140 \mathrm{~mm}$ $\pm 5 \mathrm{~mm}$ determined using the DIN 18555-2 standard (flow table test). This consistency would be suitable for a mortar used for jointing masonry. Standard EN 196-1 prisms $40 \mathrm{~mm} \times 40 \mathrm{~mm} \times 160 \mathrm{~mm}$ were produced.

The specimens were stored up to an age of seven days at $20^{\circ} \mathrm{C}$ and $95 \%$ relative humidity and demoulded as soon as possible. As an exception the samples with white lime CL90 were stored the first seven days at $23^{\circ} \mathrm{C}$ and $50 \%$ relative humidity and demoulded after three days. A storage in a wet climate is not suitable for this binder as the first "setting" occurs due to a partly vaporisation of the mixing water. After this pre-storage the further curing was as follows:

-binder CL90: $20^{\circ} \mathrm{C}$ and $65 \%$ relative humidity and weathering with 1 volume- $\% \mathrm{CO}_{2}$. The samples were immersed two times per week for $30 \mathrm{sec}$ under water. This procedure accelerates the carbonation process of air hardening lime mortars [13].

-other binders: $20^{\circ} \mathrm{C}$ and $65 \%$ relative humidity and weathering with 1 volume- $\% \mathrm{CO}_{2}$

-samples for the sulphate resistance test: $23^{\circ} \mathrm{C}$ and $50 \%$ relative humidity

\subsection{Characterization methods}

The water requirement for a flow of $140 \mathrm{~mm} \pm 5 \mathrm{~mm}$ was determined according to DIN 18555-2. The water retention capacity of the fresh mortar was measured according to DIN 18555-7.

Dynamic modulus of elasticity was tested using the resonance frequency method, flexural and compressive strength were determined according to DIN 18555-3.

The first shrinkage of lime mortars is caused by the drying shrinkage (similar as for example in loam mortars), the carbonation shrinkage and - if the 
binder contains hydraulic components - the chemical shrinkage due to the hydration reactions. With the usual techniques (e.g., according to DIN 52450) only measurements on hardened samples are possible. Especially mortars based on air hardening lime show a strong shrinkage in the early state (transition between plastic and hardened mortar). The determination of this early length change was performed by measuring the length of the empty steel mould with an accuracy of $\pm 0.01 \mathrm{~mm}$ using a slide gauge. After that the fresh mortar was filled in. The hardened prisms were demoulded as soon as possible and their length was determined using the slide gauge. The so-called shrinkage "in the mould" was calculated from the length difference between mould and specimen. The further length change was measured using the conventional technique (dilatometer). The total 1 st shrinkage results from the addition of both shrinkage values. Hygral length change was determined by immersion of the specimens in water of $20^{\circ} \mathrm{C}$ for 7 days (swelling) and subsequent drying of the specimen in the climate $20^{\circ} \mathrm{C}$ and $65 \%$ relative humidity ( 2 nd shrinkage).

The hygral properties were tested at a sample age of 56 days using $40 \mathrm{~mm} \times 40 \mathrm{~mm} \times 160 \mathrm{~mm}$ prisms with their side faces sealed. The water absorption coefficient (rate of water absorption, capillary suction) and total capillary water absorption (saturation under water at atmospheric pressure) were measured according to DIN 52617 and DIN 52103 respectively. Water desorption (drying behaviour) was determined by weighing as described in [14], method B10P, using the previously water saturated samples. As characteristic value, the amount of desorbed water after 24 hours was calculated (as percentage of the total absorbed water). The water vapour diffusion resistance was tested according to DIN 52615 (wet-cup method).

Total porosity and pore size distribution were determined by mercury intrusion porosimetry at a sample age of 90 days. Before measurement the mortar samples were reduced to a particle size of $2-4 \mathrm{~mm}$ using a pair of pincers and dried at $70^{\circ} \mathrm{C}$ for two weeks. For interpretation of the results the pore size classification described by Romberg [16] was used (air pores $>10 \mu \mathrm{m}$, capillary pores $10-0.03 \mu \mathrm{m}$, gel pores $<0.03 \mu \mathrm{m}$ ).

Freeze-thaw resistance was tested at sample age of 90 days as described in [14], method A7M. The mortar samples (three standard prisms $40 \mathrm{~mm} \times 40 \mathrm{~mm} \times$ $160 \mathrm{~mm}$ ) were saturated in water and air- and watertight sealed in transparent film. 75 cycles $+20 /-20^{\circ} \mathrm{C}$
(4 hours at each temperature) were performed. At the beginning and after 75 cycles the dynamic modulus of elasticity was measured. The reduction in E-modulus was used as criterion for the structural damages due to frost attack.

A high sulphate resistance is a very important property for restoration mortars as historical buildings often contain high amounts of soluble sulphates. The method described in [17] for testing the internal sulphate attack was used in this study. 15 weight- $\%$ of gypsum (dihydrate) was added to the binder. Mortars as described above were produced with the same water/binder ratio as the reference mortar without gypsum addition. The mortar samples were demoulded as soon as possible and cured as described in 2.2 until a sample age of 28 days. After that pre-curing the specimens were stored at $8^{\circ} \mathrm{C}$ under water. Their length change was determined using a dilatometer. The relative length change with respect to the reference sample without gypsum addition was calculated. This testing method can be regarded as very harsh because the sulphate is in direct contact with the binder phases (aluminate and ferrate phase and their hydration products), which may form expansive reaction products. In addition, the storage at low temperature is favourable for ettringite and thaumasite formation due to thermodynamic reasons. After the sulphate resistance test, the samples were investigated using $\mathrm{X}$-ray diffraction and scanning electron microscopy to determine the potential formation of the expansive phases ettringite and thaumasite.

\section{Results}

\subsection{Fresh mortar properties}

Table 2 shows the results of the fresh mortar characteristics. In general, water/binder ratio and water retention capacity are closely related to the specific surface of the binder systems. Mortars prepared from binders with a high specific surface show a high water demand for a given consistency but also a high water retention capacity.

The clay aggregate additions cause a remarkable increase of water/binder ratio up to $20 \%$. The effect of kaolin is stronger compared to loam due to its higher specific surface $\left(12600 \mathrm{~cm}^{2} / \mathrm{g}\right.$ and $7000 \mathrm{~cm}^{2} / \mathrm{g}$ respectively). It can be expected that the increased 

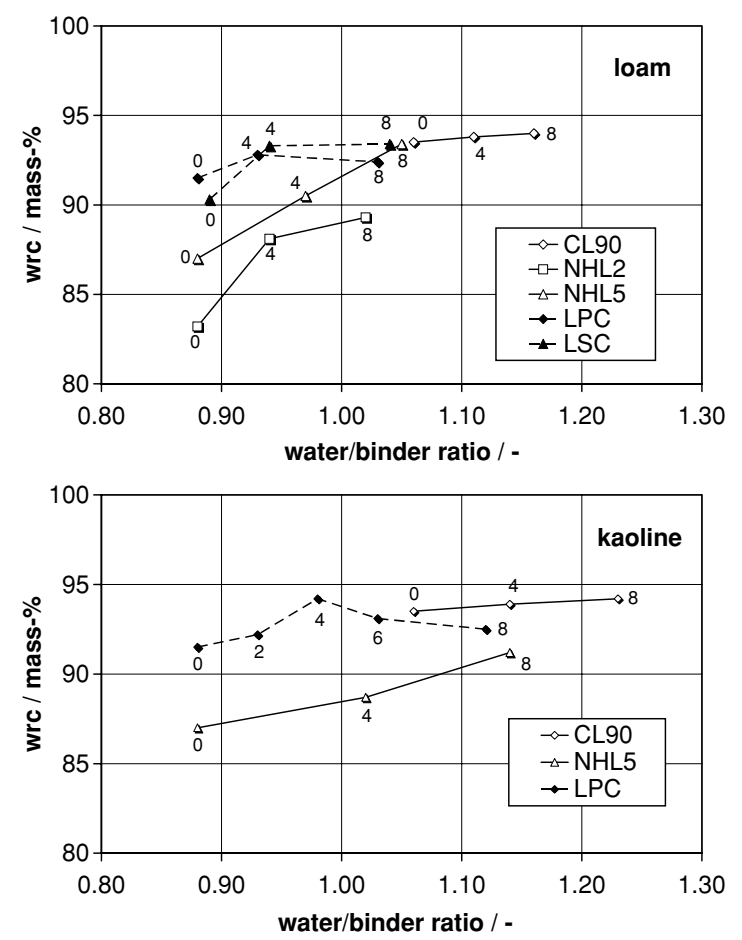

Fig. 1 Influence of clay fines on water/binder ratio and water retention capacity (numbers indicate amount of clay added).

water/binder ratios will negatively influence hardened mortar properties and durability.

The water retention capacity increases by the addition of loam and kaolin (Fig. 1). Hence, mortars with clay contents show fewer tendencies to dry out when applied to a surface with a high water absorption coefficient. This effect is related to the high specific surface of the clays but also to their water binding ability. Increasing water/binder ratio in mortars without clay additions generally has the opposite effect, a reduction of the water retention capacity.

\subsection{Mechanical properties}

The mechanical properties of the examined mortar mixes are given in Table 2. With increasing amount of clay in the aggregate a decrease in dynamic modulus of elasticity, flexural and compressive strength is found. The reduction in E-modulus and strength can be up to $50 \%$ and is related to the increase of the water/binder ratio as shown in Fig. 2 for compressive strength. The higher the water demands of the mortar, the lower are Emodulus and strength. Hence, kaolin shows a stronger effect compared to loam.
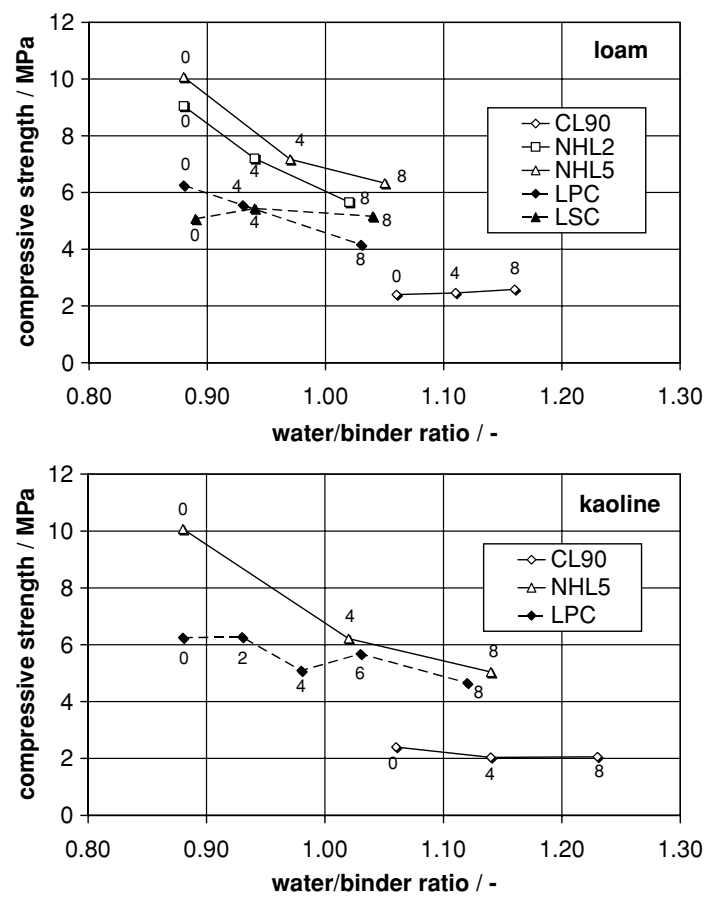

Fig. 2 Influence of clay fines on compressive strength (numbers indicate amount of clay added).

\subsection{Shrinkage and swelling}

Table 2 shows the values for 1 st shrinkage, swelling and 2nd shrinkage. The 1 st shrinkage is strongly dependant on the hydraulic binder proportions. Lime based mortars with low hydraulic proportions need only a small part of the mixing water for the formation of hydrate phases. The main portion of the mixing water is used to make the mortar workable and evaporates during drying of the mortar. Additionally, lime hydrates with low hydraulic portions have a higher specific surface and therefore a higher water demand. For these reasons, shrinkage - especially the shrinkage "in the mould" increases in the sequence NHL5 < NHL2 < CL90. Both lime-cement mortars show the lowest shrinkage.

The clay additions always increase the 1 st shrinkage, which is linked to their influence on the water/binder ratio (Fig. 3). The increasing demand of mixing water for the same consistency that is caused by the clay additions leads to an increasing 1st shrinkage. Due to the water retaining properties of the clay minerals the drying shrinkage (shrinkage "in the mould") relatively decreases with respect to the shrinkage of the hardened mortar, when loam and clay content raises. 

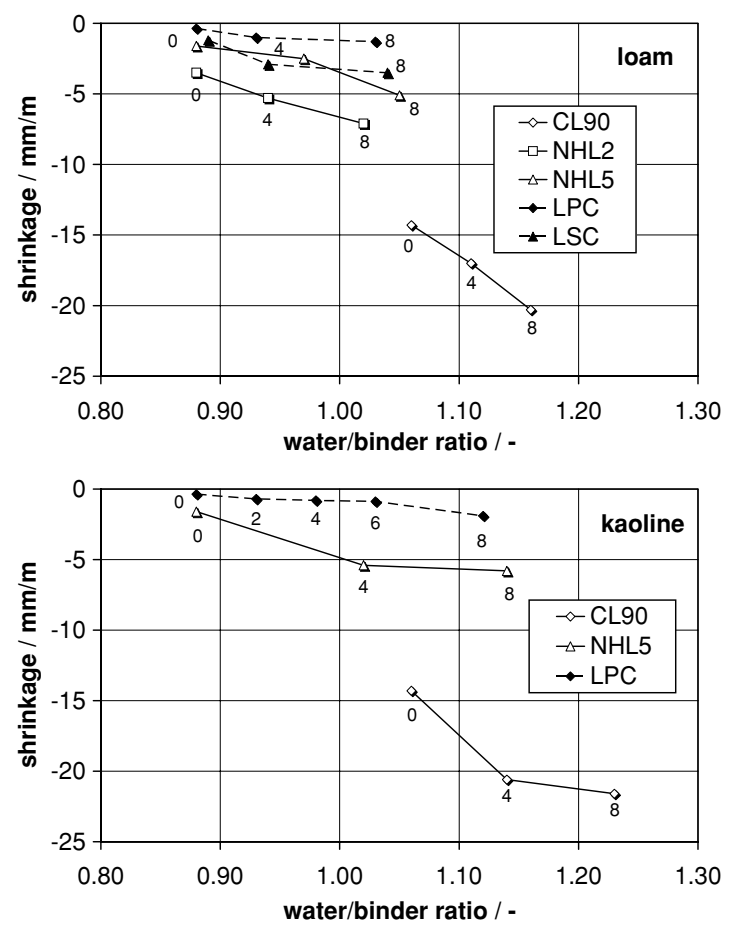

Fig. 3 Influence of clay fines on 1st shrinkage (numbers indicate amount of clay added).

Hygral swelling and 2nd shrinkage are low for the mortars without clay additions. According to [14] a maximum hygral length change of $\pm 0.30 \mathrm{~mm} / \mathrm{m}$ is recommended for restoration mortars. The clay additions increase the absolute values for swelling and 2nd shrinkage only slightly. Due to the swelling ability of clay minerals caused by water absorption a stronger effect could have been expected. Other clay minerals, especially of the smectite type (e.g., montmorillonite), should cause higher values for swelling and 2 nd shrinkage [15].

\subsection{Hygral properties}

Table 3 shows the capillary water absorption coefficient, the total capillary water absorption under atmospheric pressure, the drying behaviour (as \% of water desorbed after $24 \mathrm{~h}$ ) and the water vapour diffusion resistance.

The clay aggregate additions cause an increase of the water absorption coefficient (Fig. 4) and of the capillary absorbed water (Fig. 5) the more of this material is added. Thus, it can be concluded that clay fines in aggregates increase both the rate of water sorption
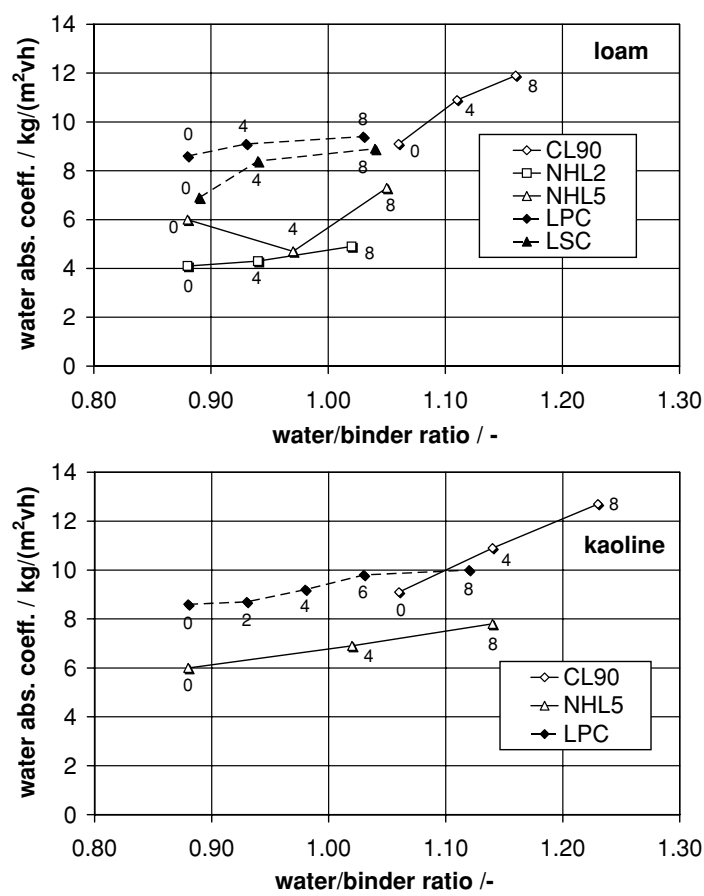

Fig. 4 Influence of clay fines on the capillary water absorption coefficient (numbers indicate amount of clay added).
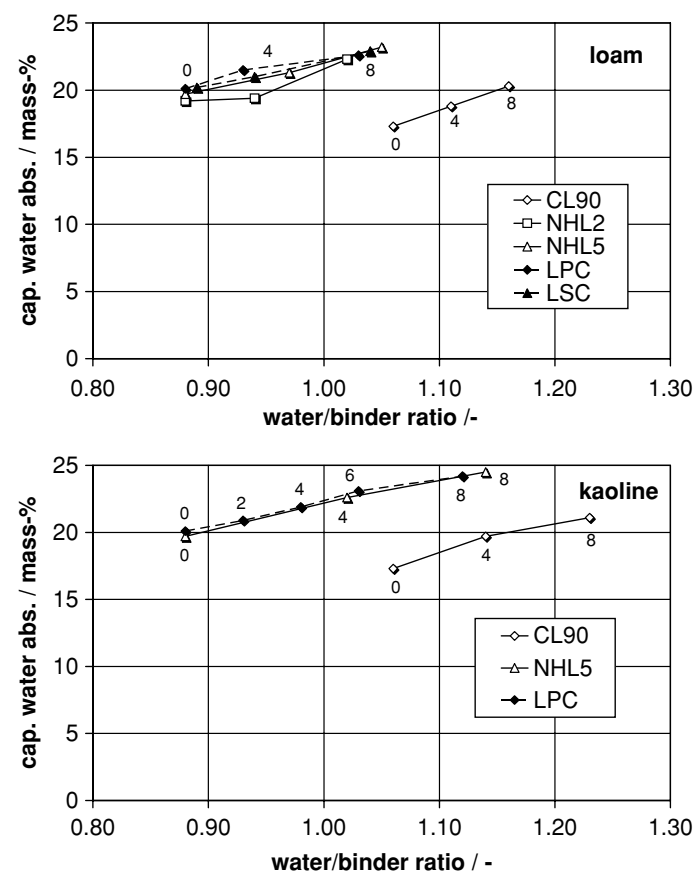

Fig. 5 Influence of clay fines on capillary water absorption (numbers indicate amount of clay added). 
Table 3 hygral properties, frost resistance and mercury intrusion porosimetry of hardened mortars

\begin{tabular}{|c|c|c|c|c|c|c|c|c|c|c|c|c|}
\hline mortar & $\begin{array}{l}\omega \\
\mathrm{kg} /\left(\mathrm{m}^{2} \sqrt{ } \mathrm{h}\right)\end{array}$ & $\begin{array}{l}\mathrm{W}_{\mathrm{abs}} \\
\text { Vol.-\% }\end{array}$ & $\begin{array}{l}\mathrm{W}_{\mathrm{des}, 24 \mathrm{~h}} \\
\%\end{array}$ & $\begin{array}{l}\mu \\
-\end{array}$ & $\begin{array}{l}\text { FTR } 75 \text { cycles } \\
\left.\text { reduction } *^{*}\right) \mathrm{E}_{\mathrm{dyn}} / \%^{*} \text { ) }\end{array}$ & $\begin{array}{l}\rho_{\text {bulk }} \\
\mathrm{g} / \mathrm{cm}^{3}\end{array}$ & $\begin{array}{l}\rho_{\text {true }} \\
\mathrm{g} / \mathrm{cm}^{3}\end{array}$ & $\begin{array}{l}\mathrm{TP} \\
\text { Vol.-\% }\end{array}$ & $\begin{array}{l}\text { AP } \\
\text { Vol.-\% }\end{array}$ & $\begin{array}{l}\text { CP } \\
\text { Vol.- \% }\end{array}$ & $\begin{array}{l}\text { GP } \\
\text { Vol.- } \%\end{array}$ & $\begin{array}{l}r \\
\mu \mathrm{m}\end{array}$ \\
\hline CL90 & 9.1 & 17.3 & 40.6 & 11.4 & samples destroyed & 1.97 & 2.61 & 24.48 & 8.64 & 14.40 & 1.42 & 1.80 \\
\hline CL90-L4 & 10.9 & 18.8 & 36.6 & 10.1 & samples destroyed & 1.93 & 2.62 & 26.17 & 6.99 & 16.89 & 2.29 & 0.65 \\
\hline CL90-L8 & 11.9 & 20.3 & 34.7 & 9.8 & samples destroyed & 1.90 & 2.64 & 28.10 & 7.80 & 17.90 & 2.39 & 0.58 \\
\hline CL90-K4 & 10.9 & 19.7 & 33.2 & 10.2 & samples destroyed & 1.88 & 2.59 & 27.35 & 7.78 & 18.10 & 1.48 & 0.64 \\
\hline CL90-K8 & 12.7 & 21.1 & 28.6 & 10.1 & samples destroyed & 1.55 & 2.70 & 30.28 & 6.77 & 21.40 & 2.14 & 0.47 \\
\hline NHL2 & 4.1 & 19.2 & 32.8 & 15.2 & 62.3 & 2.06 & 2.77 & 25.29 & 4.20 & 16.90 & 2.95 & 0.44 \\
\hline NHL2-L4 & 4.3 & 19.4 & 30.4 & 14.5 & 66.2 & 1.92 & 2.63 & 27.15 & 4.01 & 17.20 & 3.29 & 0.34 \\
\hline NHL2-L8 & 4.9 & 22.3 & 29.4 & 13.1 & 67.4 & 1.85 & 2.47 & 26.04 & 4.50 & 18.40 & 2.75 & 0.47 \\
\hline NHL5 & 6.0 & 19.7 & 34.9 & 13.1 & 68.6 & 1.92 & 2.56 & 25.25 & 3.25 & 18.40 & 3.62 & 0.41 \\
\hline NHL5-L4 & 4.7 & 21.3 & 29.0 & 13.2 & 68.8 & 1.93 & 2.61 & 26.10 & 4.24 & 18.40 & 3.47 & 0.31 \\
\hline NHL5-L8 & 7.3 & 23.2 & 27.6 & 11.5 & 72.1 & 1.92 & 2.67 & 28.01 & 4.14 & 20.12 & 3.76 & 0.28 \\
\hline NHL5-K4 & 6.9 & 22.6 & 28.4 & 12.7 & 71.5 & 1.85 & 2.51 & 26.18 & 3.90 & 19.31 & 2.96 & 0.33 \\
\hline NHL5-K8 & 7.8 & 24.5 & 28.3 & 11.2 & 71.5 & 1.88 & 2.58 & 27.34 & 4.58 & 20.50 & 3.30 & 0.35 \\
\hline LPC & 8.6 & 20.1 & 34.2 & 10.6 & 15.0 & 1.94 & 2.60 & 25.10 & 4.02 & 18.50 & 2.59 & 0.31 \\
\hline LPC-L4 & 9.1 & 21.5 & 32.4 & 10.5 & 19.0 & 1.93 & 2.62 & 26.35 & 3.78 & 19.80 & 2.77 & 0.30 \\
\hline LPC-L8 & 9.4 & 22.6 & 27.9 & 9.4 & 24.0 & 1.86 & 2.61 & 28.91 & 4.11 & 22.10 & 2.73 & 0.32 \\
\hline LPC-K2 & 8.7 & 20.9 & 32.4 & 10.3 & 8.5 & n. d. & n. d. & n. d. & n. d. & n. d. & n. d. & n. d. \\
\hline LPC-K4 & 9.2 & 21.9 & 29.3 & 10.3 & 12.9 & 1.85 & 2.59 & 28.60 & 4.46 & 21.60 & 2.57 & 0.33 \\
\hline LPC-K6 & 9.8 & 23.1 & 29.5 & 9.8 & 19.8 & n. d. & n. d. & n. d. & n. d. & n. d. & n. d. & n. d. \\
\hline LPC-K8 & 10.0 & 24.2 & 30.3 & 8.9 & 22.7 & 1.80 & 2.60 & 30.65 & 3.92 & 24.20 & 2.49 & 0.33 \\
\hline LSC & 6.9 & 20.2 & 32.8 & 11.9 & 3.8 & 1.95 & 2.61 & 25.72 & 3.64 & 19.25 & 2.82 & 0.33 \\
\hline LSC-L4 & 8.4 & 21.0 & 26.6 & 11.1 & 22.3 & 1.93 & 2.61 & 25.99 & 3.67 & 19.41 & 2.92 & 0.25 \\
\hline LSC-L8 & 8.9 & 22.9 & 26.5 & 10.0 & 65.2 & 1.87 & 2.59 & 27.82 & 3.68 & 21.10 & 3.04 & 0.29 \\
\hline
\end{tabular}

$\omega: \quad$ capillary water absorption coefficient

$\mathrm{W}_{\mathrm{abs}}$ : capillary water absorption

$\mathrm{W}_{\mathrm{des} 24}$ : desorbed water after $24 \mathrm{~h}$ (as \% of adsorbed water) $\quad \mu$ : water vapour diffusion resistance

FTR: freeze-thaw resistance as E-Modulus reduction in $\%$ after 75 cycles

$\rho_{\text {bulk }}:$ bulk density $\quad \rho_{\text {true }}:$ true density

AP: $\quad$ air pores $>10^{2} \mu \mathrm{m}$

r: medium pore radius
CP: capillary pores $10^{2}-10^{-2} \mu \mathrm{m}$

n. d.: not determined
TP: total porosity

GP: $\quad$ gel pores $<10^{-2} \mu \mathrm{m}$ and the total amount of water absorbed in the mortar. Also in this case, this effect is related to the water/binder ratio. With increasing water/binder ratio the mortar contains an increasing part of the mixing water that is not needed for hydration reactions. When this part of the mixing water evaporates, capillary pores are left which play an important role in water transport. High capillary pore contents usually have a negative effect on durability, for example on frost resistance.

The clay additions slow down the drying-out of the mortar samples (Fig. 6). This effect is caused by their water-retaining action. Historical lime mortars usually show a quick drying-out [13].

The water vapour diffusion resistance of all examined mortar samples is very low. This is typical for lime-based mortars that have not been modified by admixtures. The water vapour diffusion resistance tends to decrease slightly with increasing clay content. This can also be explained by the increasing capillary pore content.

\subsection{Mercury intrusion porosimetry}

Table 3 shows the results. The clay fines increase total porosity. This effect is mainly caused by a raise in capillary porosity that is linked to the increasing water/binder ratio (Fig. 7). This also causes the faster and higher water absorption and the decreasing water vapour diffusion resistance. Kaolin influences the capillary pore content stronger than loam.

The median pore radius is slightly decreased in most cases by the addition of clay fines in mortars on the basis of hydraulic lime and lime-cement. In the binder system CL90 the clay minerals cause a decrease of the median pore radius from $1.80 \mu \mathrm{m}$ to values around $0.50 \mu \mathrm{m}$. 

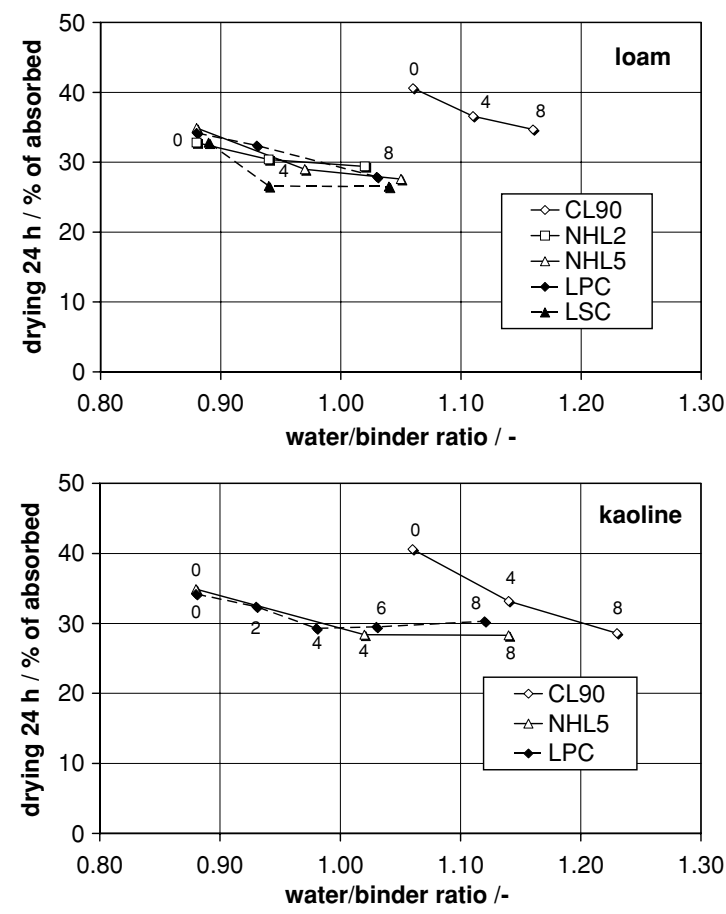

Fig. 6 Influence of clay fines on drying behaviour (numbers indicate amount of clay added).
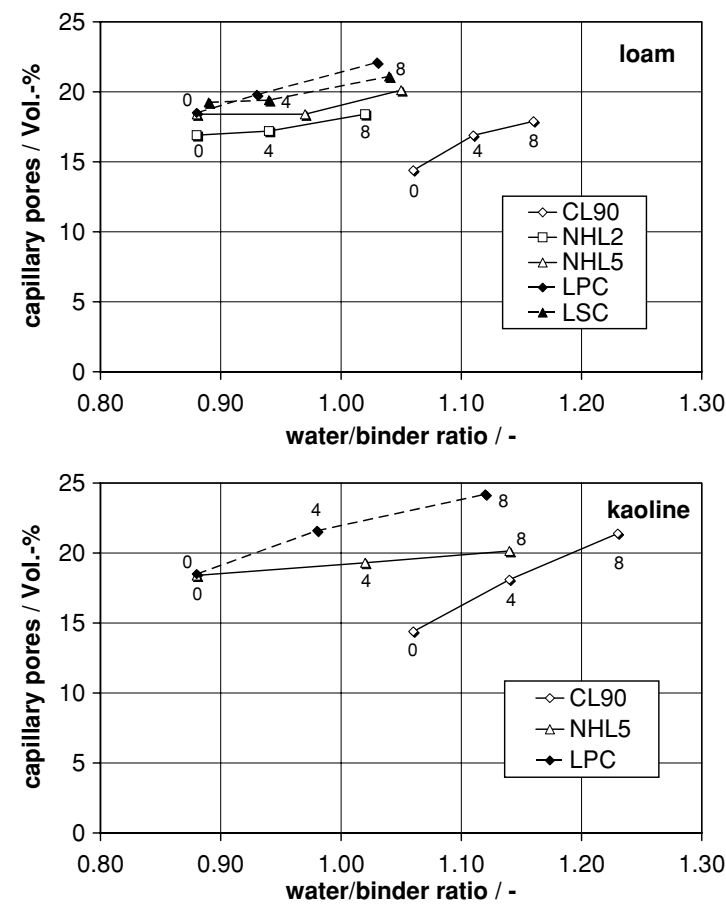

Fig. 7 Influence of clay fines on capillary porosity estimated by mercury intrusion porosimetry (numbers indicate amount of clay added).
These low values are similar to those of the binders with hydraulic proportions.

This effect may indicate a hydraulic reaction between calcium hydroxide and the clay minerals.

The median pore radius correlates well with the drying behaviour of the mortar samples, as shown by [13].

\subsection{Freeze-thaw resistance}

The reference mortar on the basis of air hardening lime has a very poor freeze-thaw resistance (Table 3 ). Even at the minimum requirement according to [14] (15 cycles $\pm 20^{\circ} \mathrm{C}$ ) all specimens show a strong cracking. This is in good agreement with previous investigations [18]. The samples with binder CL90 and additions of loam or clay show a strong cracking and also a loss of material. After 75 cycles all CL90 samples were almost completely destroyed, thus a determination of elastic modulus was not possible.

The mortars on the basis of hydraulic lime (NHL2 and NHL5) show also strong damages. The decrease in elastic modulus gets stronger when loam or clay is added to the aggregate.

Concerning freeze-thaw resistance lime-cement mortars are more durable compared to hydraulic limes. Especially in the lime-slag cement system a strong negative effect of clay and loam additions on the durability can be observed. The LSC mortar without loam addition shows a decrease of elastic modulus by $4 \%$ after 75 freeze-thaw cycles. An addition of $4 \%$ loam causes a decrease by about $25 \%$, the sample with $8 \%$ loam shows a decrease by approximately $75 \%$.

\subsection{Sulfate resistance}

Concerning the mortars without addition of loam or clay the results of the sulphate resistance test reveal, that the samples with hydraulic lime as binder show a strong expansion that leads to a complete destruction of the specimens after 1-2 weeks of testing. Also both limecement mortars showed strong expansion and cracking after several weeks. This is in good agreement to previous studies [18].

The influence of loam and clay additions on sulphate resistance of lime-based mortars is displayed in Fig. 8. All hydraulic mortars show a strong expansion after several weeks of testing. Concerning the expansion, a negative influence of clay fines on sulphate resistance could not clearly be determined. As a tendency 


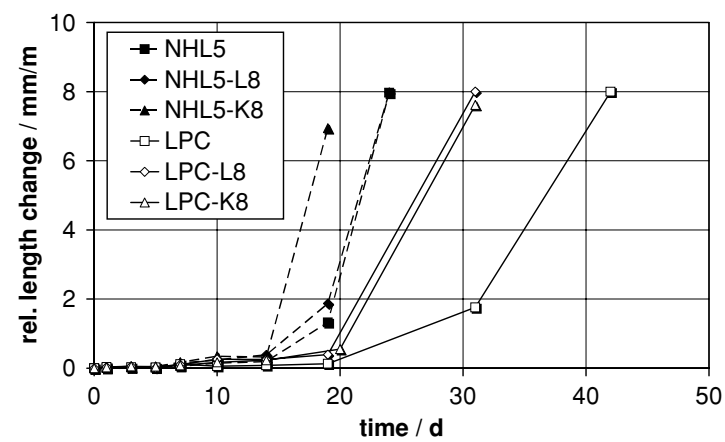

Fig. 8 Influence of clay fines on sulphate resistance.

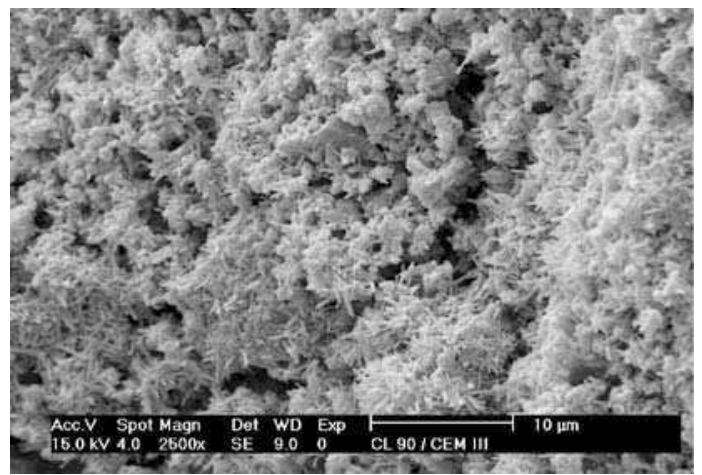

Fig. 9 SEM image of mortar LSC after sulphate resistance test. Needle-type ettringite has crystallized in the mortar structure.

however, a slightly earlier occurrence of the expansion reaction can be recognized.

Ettringite could be identified by X-ray diffraction in all degraded mortar specimens. Thaumasite did not occur in any sample. Mortars with binder CL90 and added loam or clay did not contain ettringite or thaumasite in quantities that could be determined by X-ray diffraction.

In comparison to the samples without clay, a stronger ettringite formation of the loam or kaolin containing mortars after the sulphate resistance test is observed using scanning electron microscopy (SEM). Fig. 9 and Fig. 10 show this influence clearly on the example of the LSC mortars without and with addition of $8 \%$ loam to the aggregate.

The ettringite formation occurs mainly on the surface of the clay minerals. This can even be observed for mortars without any hydraulic constituents (binder CL90). Figure 11 shows that - as expected - no ettringite has been formed in mortar CL90 during the sulphate resistance test. With the same resolution of the SEM-image also in the kaolin containing sample

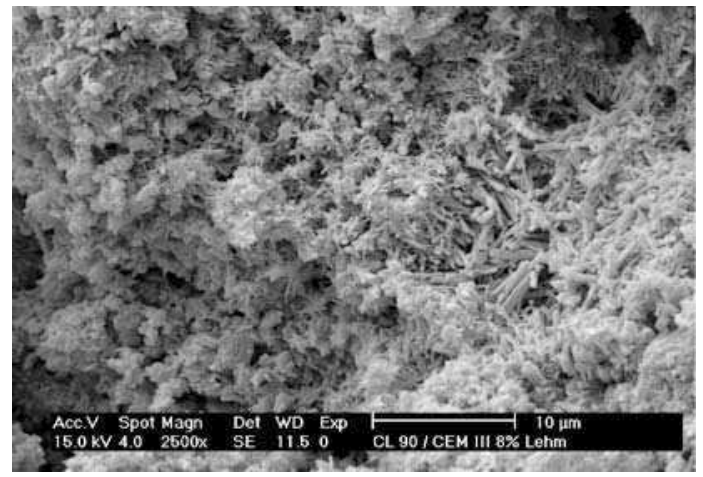

Fig. 10 SEM image of mortar LSC-L8 after sulphate resistance test. More and larger ettringite crystals as in Figure 9.

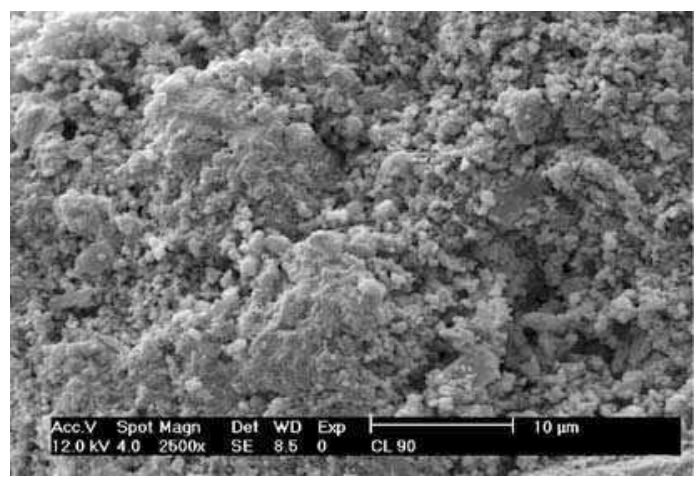

Fig. 11 SEM-image of mortar CL90 after sulphate resistance test. No ettringite crystals.

no ettringite can be found (Fig. 12). Using a higher magnification, ettringite formation could be observed on the surface of the kaolin crystals (Fig. 13). Also in the samples containing loam, an ettringite formation on the surface of the clay minerals occurs (Fig. 14). From these results it can be concluded, that clay containing aggregates may serve as aluminium source for the formation of the expansive mineral ettringite in the case of sulphate attack.

\section{Conclusions}

Increasing amounts of clay fines in the aggregates influence the fresh mortar properties as follows:

Clay minerals lead to a higher water requirement for a given consistency, thus improving workability. The increase of the amount of mixing water does not lead to a decrease of the water retention capacity due to the water retaining properties of the clay minerals. Therefore, the clay fines improve the fresh mortar characteristics. 


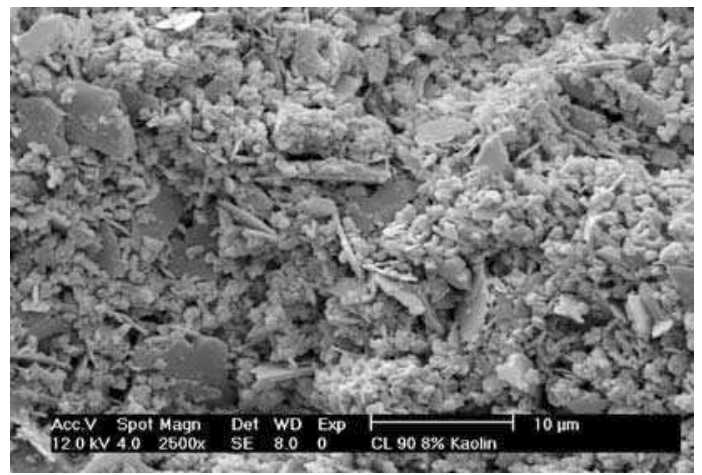

Fig. 12 SEM-image of mortar CL90-K8 after sulphate resistance test. Plate-shaped kaolin crystals. At this magnification no ettringite can be observed.

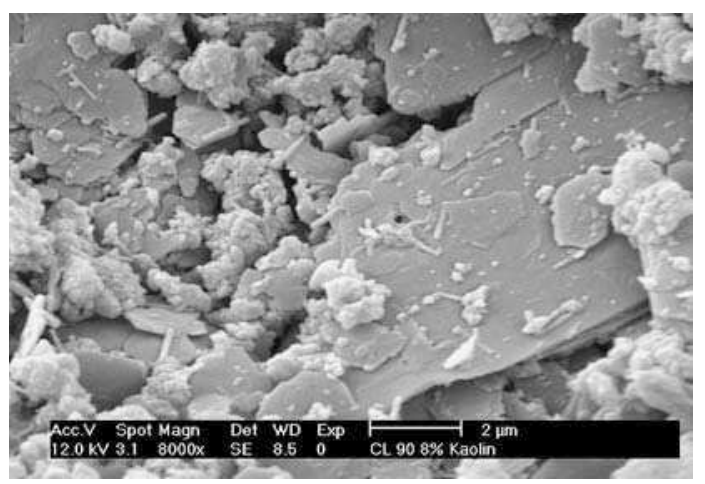

Fig. 13 SEM-image of mortar CL90-K8 after sulphate resistance test. Formation of ettringite crystals on the surface of the kaoline.

However, the increase in water demand causes a strong decrease in the quality of the mortar concerning mechanical, hygral and durability properties:

Compressive strength, flexural strength and dynamic modulus of elasticity are reduced by up to $50 \%$. Strictly speaking this cannot be regarded as negative, as historical mortars often show similar mechanical characteristics. However, low strength is often linked to a poor durability.

The 1st shrinkage increases to a large extent, for example in mortars with binder NHL5 from $1.6 \mathrm{~mm} / \mathrm{m}$ without clay fines to $5.8 \mathrm{~mm} / \mathrm{m}$ with the addition of 8 weight-\% kaolin. A strong shrinkage may lead to the formation of cracks which reduce mortar durability.

The rate of water absorption is faster (increase of water absorption coefficient) and total absorption is higher. Also this effect cannot generally be considered as negative, because historical mortars may have similar hygral properties. The increase in water absorption

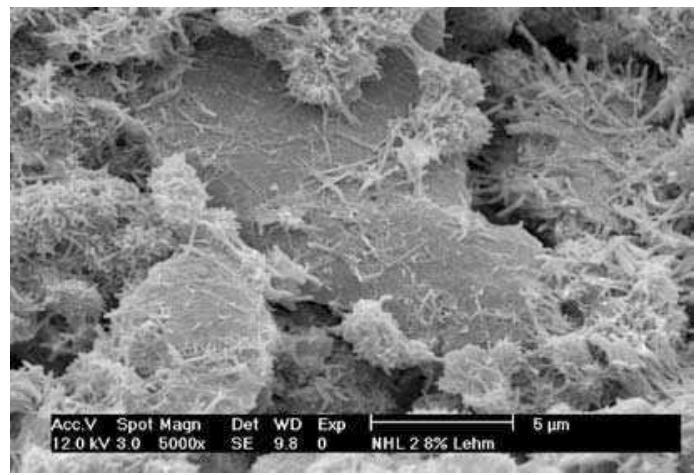

Fig. 14 SEM-image of mortar NHL2-L8 after sulphate resistance test. Ettringite formation on the surface of the clay minerals.

correlates well with an increase in capillary pore content determined by mercury intrusion porosimetry. Generally, an increase of the capillary pore content results in a lowered freeze-thaw resistance, if a sufficient amount of air voids is not present.

The drying-out of water saturated samples is slowed down with increasing amounts of clay minerals in the aggregates. This can be regarded as negative concerning the adaptation to the characteristics of historical mortars and to durability applications.

Clay fines decrease the resistance to water vapour diffusion, which can be regarded as positive with respect to restoration purposes.

Freeze-thaw resistance is lowered if aggregates containing clay minerals are used. This is linked to the higher capillary pore content caused by the increased water demand.

Clay fines have a negative influence on the sulphate resistance. SEM investigations revealed that clay minerals may act as aluminium source for the formation of the expansive mineral phase ettringite.

As a consequence of the experimental results, it can be concluded that clay minerals in the fine aggregate fraction below $63 \mu \mathrm{m}$ have a negative influence on the durability of lime-based mortars. Unwashed aggregates should not be used as mortar sands without further investigation of their clay content. If a high content of fines is required, quartz or limestone powder should be used.

In the case of a colour adaptation of the restoration mortar to the historical material, an aggregate should be used, which colour does not result from clay minerals. As an alternative, colour pigments can be applied. 
Acknowledgements The authors express their special thanks to Prof. Dr. rer. nat. Dietbert Knöfel (Berlin, Germany), formerly head of the Institute for Building and Materials Chemistry at the University of Siegen (Germany), to make this project possible. We also wish to thank Dipl.-Ing. (FH) Roger Moritz for his assistance on the practical part of this study.

\section{References}

1. Arnold B, Burger H, Neumann H-H, Obermeier C, Wens R (1997) Research and conservation of historical plasters and mortars with regard to environmental damages. Proceedings of the 13th International Conference on Building Materials (ibausil), Weimar, Germany, Sept. 2:939-948 (only available in German).

2. Franken S, Müller HS (1999) Investigations on the frost/deicing resistance of lime mortars. Proceedings of the 5th International WTA-Colloquium on Materials Science and Restoration, Esslingen, Germany, Nov., 2:927-936 (only available in German).

3. Arnold B (1998) Medieval plasters and mortars in the federal state Brandenburg. Arbeitshefte des Brandenburgischen Landesamtes für Denkmalpflege pp. 139-140 (only available in German).

4. Zier H-W, Weise G (1989) Investigations on the determination of the connection between mix proportions, aggregate parameters and compressive strengths of rendering mortars. Betontechnik 10:27-30 (only available in German).

5. Balkowski D (1982) Cracking of rendering mortars applied to ancient surfaces-causes and avoidance. Bausanierung 3:97-100 (only available in German).

6. Ramirez JL, Barcena JM, Urreta JI (1987) Sables calcaires à fines calcaires et argileuses: influence et nocivité dans les mortiers de ciment. Materials and Structures, 20:202213.

7. Sims I, Brown B (1998) Concrete aggregates, in: Leás Chemistry of Cement and Concrete, 4th edition (editor P. C. Hewlett. Butterworth-Heinemann, Oxford, UK, 907-1015.
8. He C, Makovicky E, Osbæck B (2000) Thermal stability and pozzolanic activity of raw and calcined mixed-layer mica/smectite. Applied Clay Science 17:141-161.

9. Choquette M, Bérubé M-A, Locat J (1987) Mineralogical and microtextural changes associated with lime stabilisation of marine clays from eastern Canada. Applied Clay Science 2:215-232.

10. Kollmann H (1978) Mineralogical investigations on efflorescence and expansive phenomena of building materials caused by sulphates, Giessener Geologische Schriften, Nr. 18 (only available in German).

11. Leifeld G, Münchberg G, Stegmaier W (1970) Ettringite and thaumasite as origin of expansive reactions in lime-gypsumplasters. Zement-Kalk-Gips 23:174-177 (only available in German).

12. Scullion T, Harris P (1988) Forensic evaluation of three failed cement-treated base pavements. Transportation Research Record 1611:10-18.

13. Böttger KG (1997) Mortars for the preservation of historical lime plasters, $\mathrm{PhD}$ thesis, University of Weimar (Germany), (only available in German).

14. Knöfel D, Schubert P 1993 (Editors), Handbook mortars and stone replacement materials for the preservation of historical buildings (Ernst \& Sohn Berlin, Germany, (only available in German).

15. Tucker ME (2001) Sedimentary Petrology, 3rd edition (Blackwell Science).

16. Romberg H (1978) Pores in hardened cement paste and concrete properties. Beton-Information 5: 50-55 (only available in German).

17. Henkel S, Knöfel D (1994) On the chemical compatibility of restoration mortars and masonry containing high amounts of sulphate. Proceedings of the 12th International Conference on Building Materials (ibausil), Weimar, Germany, Sept. 2:58-66 (only available in German).

18. Winnefeld F, Böttger KG, Knöfel D 1996 Properties of hydrated limes with different hydraulic contents - a critical viewing with regard to the use in preservation of historical buildings, Proceedings of the 4th International WTAColloquium on Materials Science and Restoration, Esslingen, Germany), Dez. 2: 801-815 (only available in German). 